\title{
FACTORS IN THE FORMATION OF SINUOUS AND HUMPED REE PATTERNS IN GARNET FROM MANTLE HARZBURGITE ASSEMBLAGES
}

\author{
Tim Ivanic $^{1}$, Ben Harte ${ }^{1}$, Simon Burgess ${ }^{1}$ and John Gurney ${ }^{2}$ \\ ${ }^{1}$ University of Edinburgh, Edinburgh, Scotland, U.K. \\ ${ }^{2}$ University of Cape Town, Rondebosch, South Africa
}

The chondrite-normalised relative abundance patterns for rare earth elements (REE) in many garnets from mantle harzburgite parageneses have a humped or sinuous shape and most particularly a maximum (or 'hump') in abundance in the MREE e.g. Shimizu \& Richardson (1987); Hoal et al. (1994). This is often seen as being at variance with the basic observation that for garnet the element compatibility increases in the order: light rare earth elements (LREE) to MREE to HREE (i.e. increases with decreasing ionic radius). Shimizu and Richardson (1987) suggest that any melt compositions which might be in equilibrium with humped garnet REE profiles are unlikely because such melts are not observed as igneous rocks on the Earth's surface. However, McKenzie (1989) points out that low volume metasomatic melts percolating through lithospheric peridotite probably freeze at depth and rarely, if ever, get erupted.

Most of the models of the formation of 'humped' garnet REE profiles in the literature involve dsequilibrium associated with variations in partition coefficients and diffusion parameters. We wish to emphasise the possibility that the humped REE profile garnets could be in equilibrium with melt and that the extremely LREE-enriched nature of that melt could itself be a product of garnet fractionation.

\section{Disequilibrium reaction models, Hoal et al. (1994) and Shimizu (1999)}

A model of disequilibrium processes has been invoked by Hoal et al. (1994), Shimizu \& Sobolev (1995) and Shimizu (1999) who suggest that the order of magnitude variations in partition coefficients between the LREEs $(<0.1)$ and HREEs $(<1)$ will effectively produce independent behavior in the light, middle and heavy REEs. Disequilibrium is therefore achieved by the ability of LREEs to equilibrate faster in alteration processes than the HREEs and the diffusivities of the LREE should be higher. The model proposed is that of partial re-equilibration of a refractory garnet with an extremely LREE-enriched, HREE-depleted fluid (Fig. 1). Shimizu (1999) has emphasised short time scales for these processes, but estimated diffusion coefficient values vary by 2-3 orders of magnitude (Van Orman et al. 2001b), which makes it hard to distinguish times scales of $1 \mathrm{Ma}$ to $100 \mathrm{Ma}$. Griffin et al. (1999) note a difficulty with this model in explaining the fact that some garnet cores are richer in LREE and poorer in HREE than the rim. They also suggest that it is unlikely that the larger LREE would diffuse faster than the HREE.

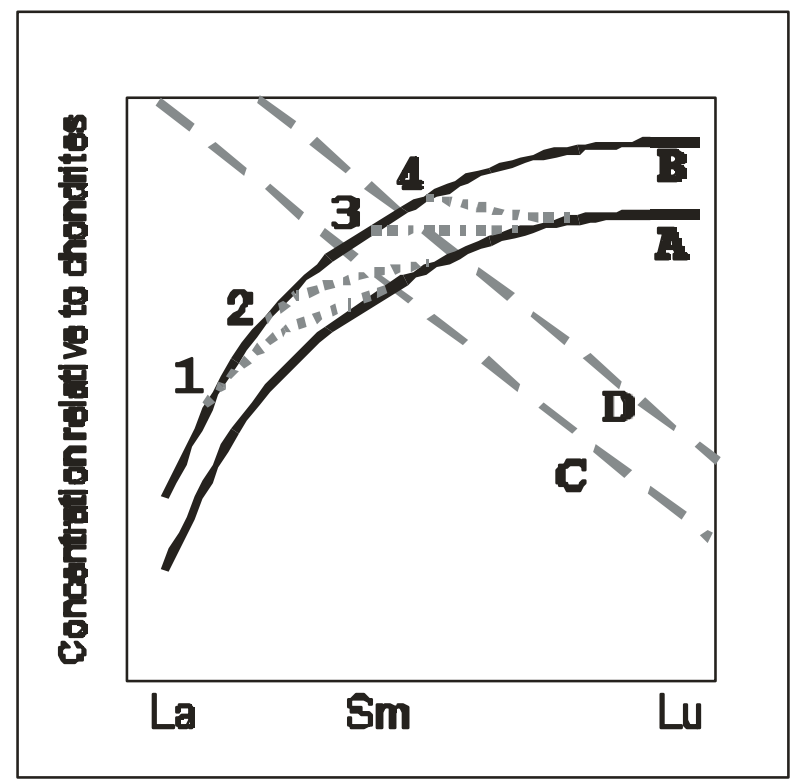

Figure 1: Schematic illustration of the generation of humped REE profiles in garnet by disequilibrium processes. Modified from Shimizu (1999). A is the initial garnet composition, B the final garnet composition, $\mathbf{C}$ the melt in equilibrium with the initial garnet and $\mathbf{D}$ the metasomatic fluid. Intermediate lines between $\mathbf{A}$ and $\mathbf{B}$ are diffusion-controlled profiles 1-4 representing progressive degrees of diffusion.

\section{Diffusion controlled reaction model, Griffin et al. (1999)}

This model considers garnet transect profiles in light of diffusion processes outlined by minor element zoning. They ascribe the generation of humped REE profiles to simple diffusion as a pre-existing garnet equilibrated with a metasomatic fluid. The diffusion model appears to require three main conditions: (1) that there is a marked change in D for different REEs, (2) that there is a maximum $D$ for LREE \& MREE and a minimum in 
HREE and (3) that the temperature-time closure point commonly changes between LREE and HREE at NdSm. However, REE diffusion data show little change from $\mathrm{La}$ to $\mathrm{Lu}$ (Van Orman et al. 2001b) and the common closure point of item (3) is unlikely if a range of mantle temperatures is accepted. A diffusion-based model should therefore imply varying break off points for the hump depending on temperature-time relationships.

\section{Fractional crystallisation model}

Burgess (1997) and Burgess \& Harte (1998) derived a succession of melts from an initial liquid compositions based on megacryst compositions from the Jagersfontein kimberlite pipe, South Africa. The model melts derived by fractional crystallisation of garnet proceeded to very high LREE/HREE and were in equilibrium with garnets showing humped REE profiles. This model assumes local equilibrium between garnet and melt and postulates that garnet fractionation arises as metasomatic melt percolates through mantle peridotite (Burgess and Harte, 1999). The model is sensitive to partition coefficients at various temperatures and the phases that are fractionally crystallising. In order to test the sensitivity of the calculations to the variation in the partition coefficients, two sets of data were used: (a) Shimizu and Kushiro (1975) and (b) data from Burgess (1997) based on Harte et al. (1996). La and Lu were omitted because of very limited data on their partition coefficients.

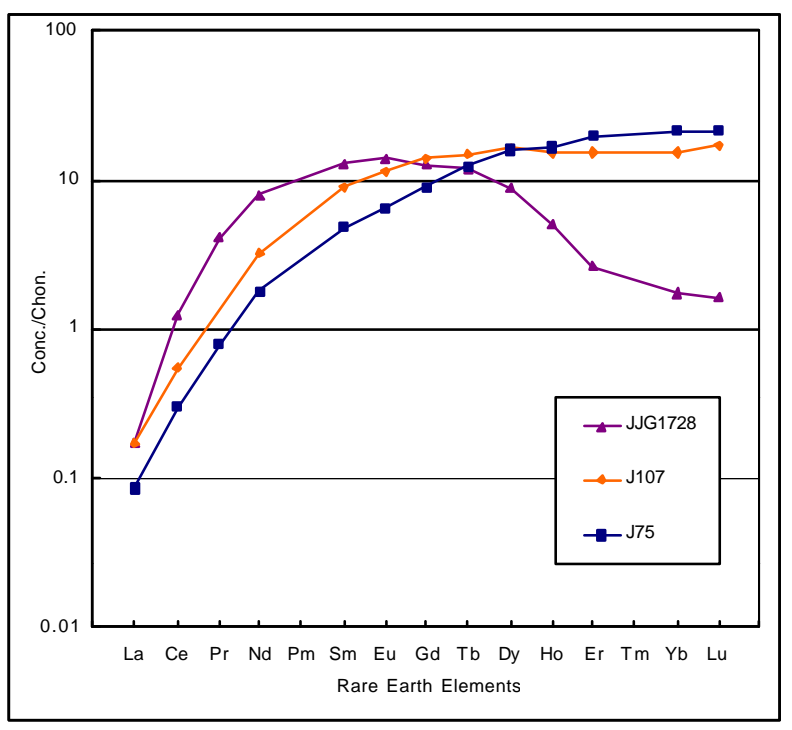

Figure 2 : REE profiles of J75, J107 and JJG1728.

The data are illustrated using three garnets from Jagersfontein xenoliths that show marked variations in their REE profiles (fig. 2). Sample J75 represents an average of all measured megacrysts studied by Burgess (1997) and has a 'normal' garnet profile of low LREE and high HREE (Fig. 2). J107 is intermediate between J75 and JJG1728, the latter of which has the most extreme MREE hump at $\sim 10$ times chondrite. Rayleigh fractionation models were applied to the initial melts (liquid in equilibrium with $\mathrm{J} 75$ megacryst garnet). In the first case (shown in Fig. 3), garnet was the only fractionating phase and, in the second case, garnet, olivine and clinopyroxene were fractionated (Fig 4). Melts in equilibrium with analyzed and modeled garnet compositions were calculated using the sets of partition coefficients referred to above.
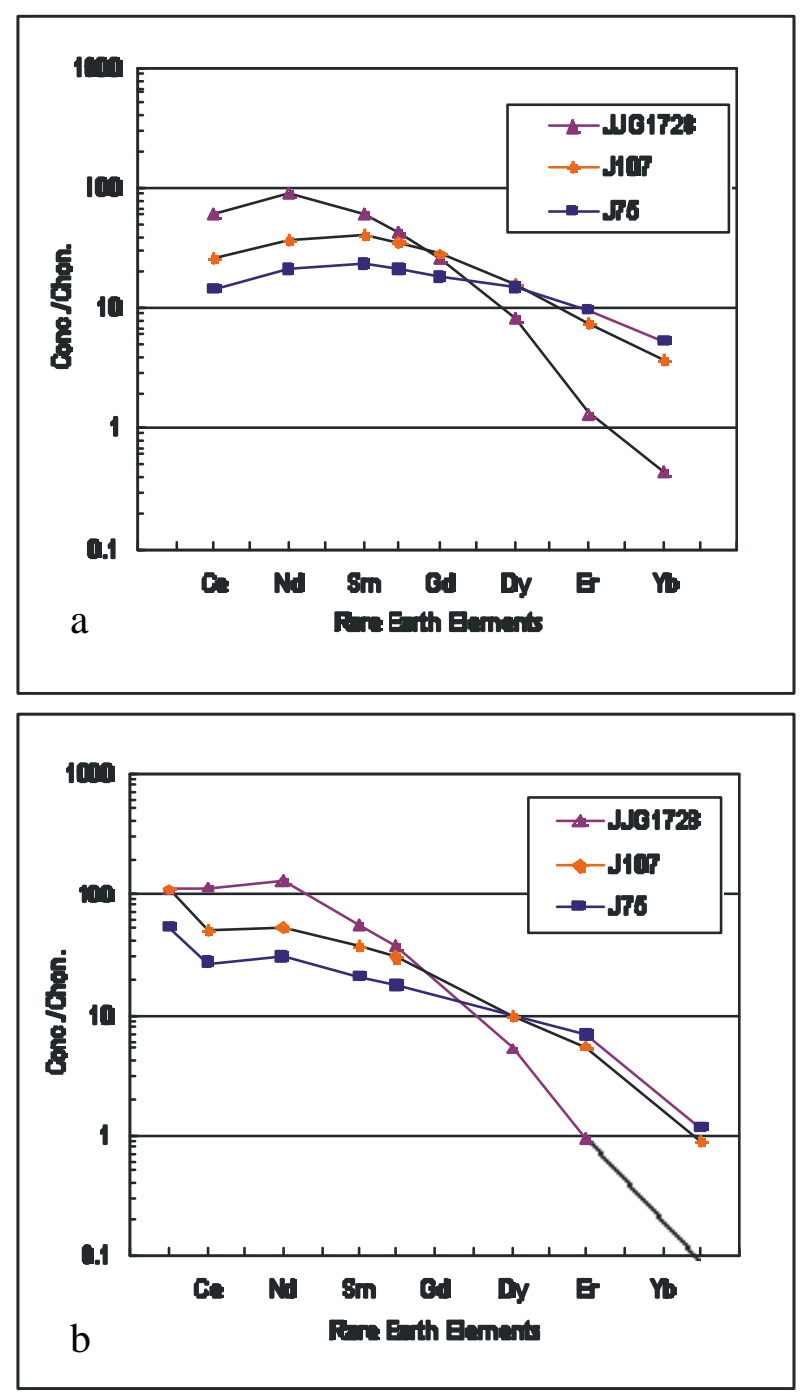

Figure 5: a Liquids in equilibrium with garnets J75, J107 and JJG1728 using Shimizu \& Kushiro (1975) partition coefficients. b as a but using Burgess (1997) partition coefficients. 

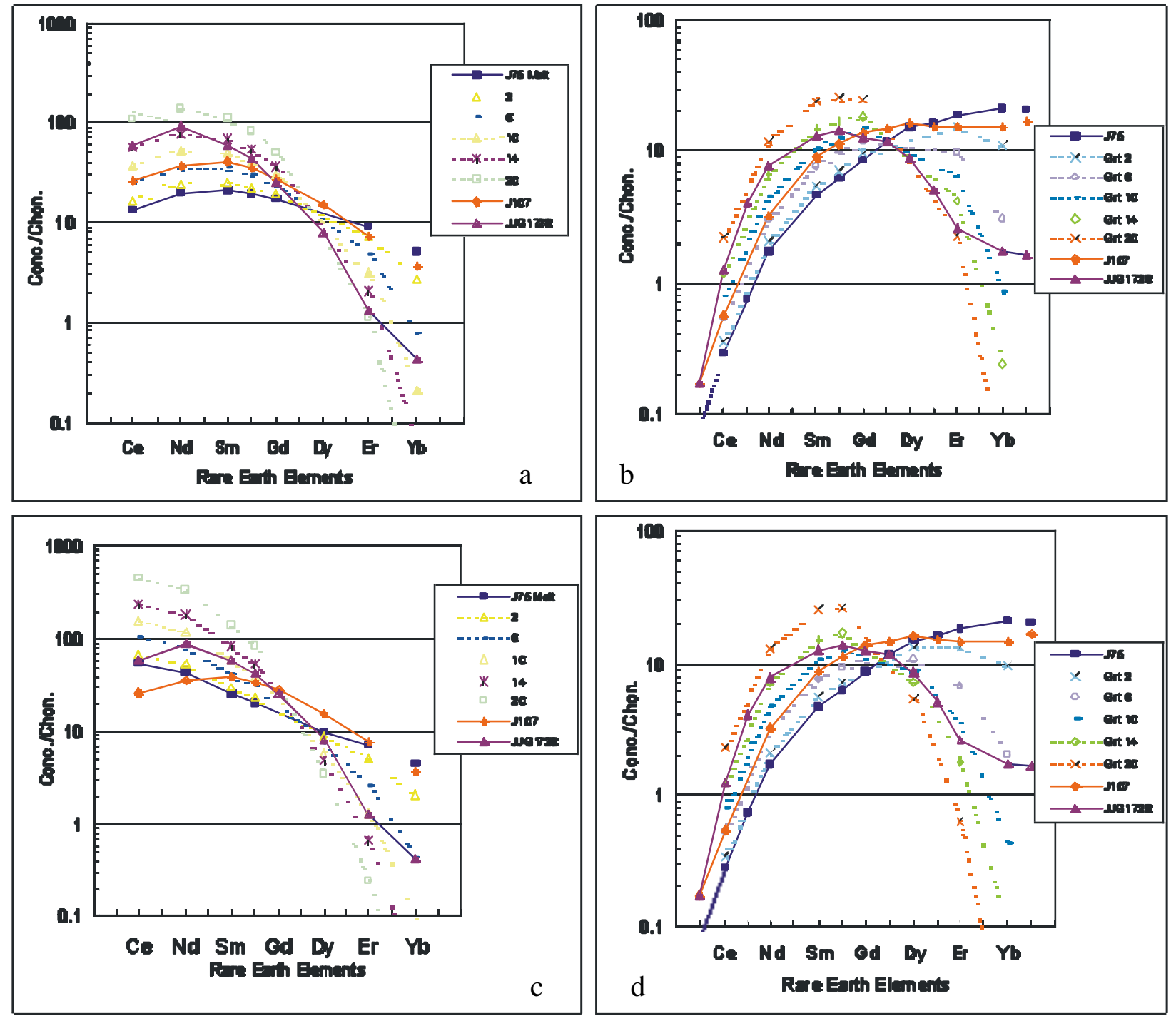

Figure 3: a Liquids in equilibrium with garnets, using Shimizu \& Kushiro (1975) partition coefficients, derived by fractional crystallisation of garnet. Numbers (2..6..10..etc.) indicate number of stages of $10 \%$ fractionation. b garnets in equilibrium with a. c \& $\mathbf{d}$ as for $\mathbf{a}$ and $\mathbf{b}$ but using Burgess (1997) partition coefficients. 

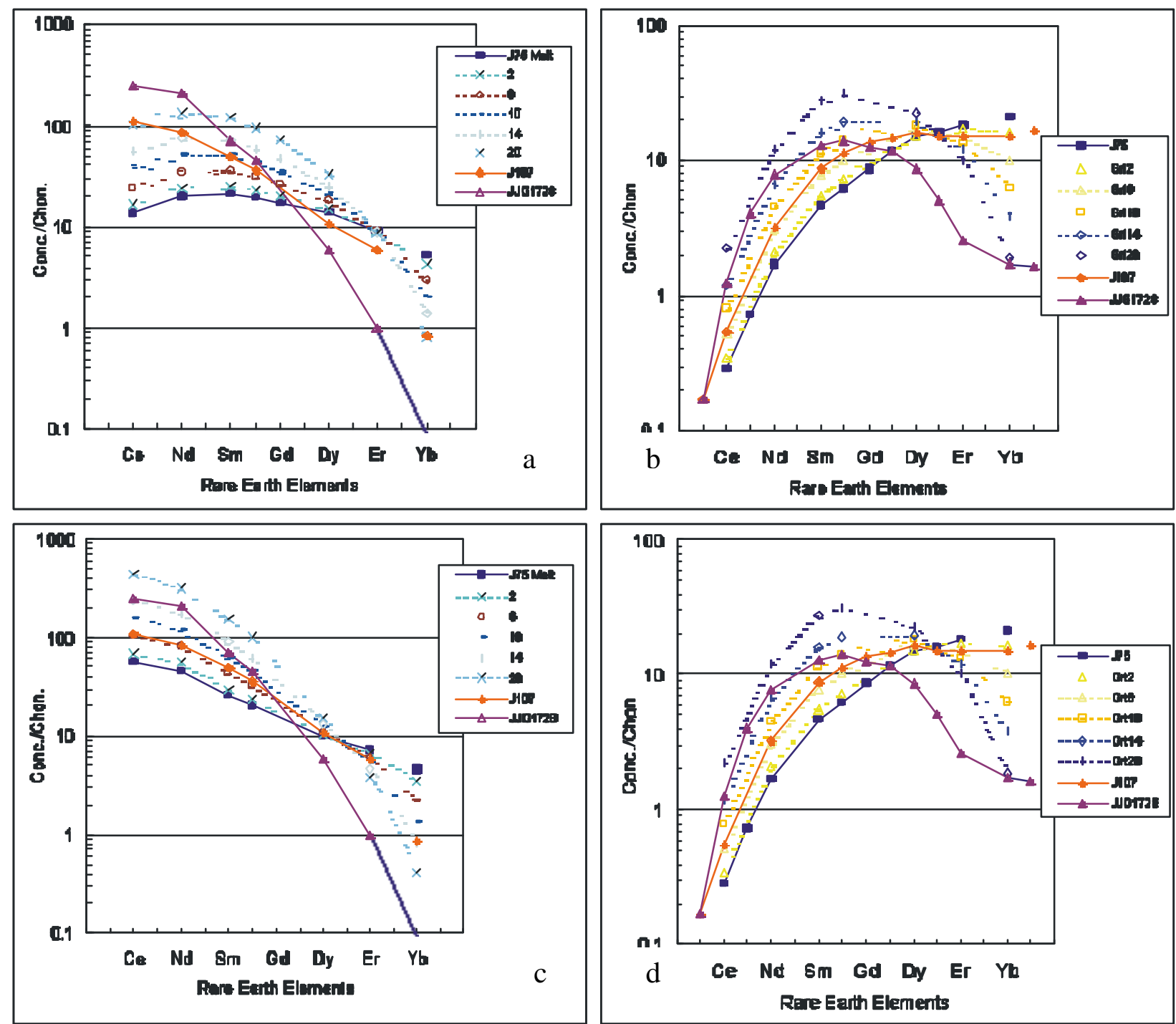

Figure 4: a Liquids in equilibrium with garnets, using Shimizu \& Kushiro (1975) partition coefficients, derived by fractional crystallisation of garnet, olivine and clinopyroxene $(2: 1: 1)$. Numbers (2..6..10..etc.) indicate number of stages of $10 \%$ fractionation. $\mathbf{b}$ garnets in equilibrium with $\mathbf{a} . \mathbf{c} \& \mathbf{d}$ as for $\mathbf{a}$ and $\mathbf{b}$ but using Burgess (1997) partition coefficients. 
Fundamentally the compositional profiles of the melt curves are similar using both sets of partition coefficients and there were no major deviations from a linear array (Fig. 5). However, the position of the hump in the associated garnets is sensitive to the partition coefficients used. Figure 4 shows that the shapes of the profiles in garnet are fundamentally the same when fractionating olivine and clinopyroxene as well as garnet. The effects of varying temperature and the ratio of phases fractionated were also tested and although the position of the hump in the REE spectrum is affected, the formation of the hump is a common product of fractionation, so long as garnet is a significant member of the fractionating crystals. We emphasise that the above suggestion shows that local disequilibrium is not necessary in the formation of humped REE profiles.

\section{CONCLUSIONS}

Several workers have emphasised the need for disequilibrium processes in producing humped garnet REE profiles, but these stem in part from a belief that the humped shaped profiles cannot be in equilibrium with possible melt compositions. Griffin et al. (1999) suggest the humped profiles result from diffusional reequilibration under appropriate circumstances. However, available diffusional parameters for the REE do not suggest a marked change in diffusion coefficients or their closure temperatures within the REE.

We suggest that equilibrium with highly LREEenriched metasomatic melts is quite possible for the humped garnet profiles. The formation of such LREEenriched melts may well result from fractional crystallisation. In this fractional crystallisation process the garnet itself plays the major role in generating the extreme LREE enrichment because of its widely varying partition coefficients (from $<1$ to $>1$ ). Thus one may view the humped REE patterns in garnet as being controlled or pre-ordained by the garnet itself.

Tim Ivanic acknowledges provision of a research studentship by NERC (U.K.).

\section{REFERENCES}

Burgess, S.R., 1997. The Evolution of the sub-cratonic mantle seen in mantle xenoliths. Ph.D. Thesis, Univers ity of Edinburgh, Scotland.

Burgess, S.R., Harte, B., 1998. Tracing lithosphere evolution through the analysis of heterogeneous G9/G10 garnets in peridotite xenoliths. Ext Abstrts, $5^{\text {th }}$ IKC, Cape Town, pp. 122-126.

Burgess, S.R., Harte B., 1999. Tracing Lithosphere Evolution Through the Analysis of Heterogeneous G9/G10 Garnets in Peridotite Xenoliths, I: Major Element Chemistry. In: Gurney J.J., et al. (Eds.), Proceedings of the VII ${ }^{\text {th }}$ International Kimberlite Conference. Red Roof Design, Cape Town, South Africa, pp. 66-80.

Griffin, W.L., Shee, S.R., Ryan, C.G., Win, T.T., Wyatt, B.A., 1999. Harzburgite to lherzolite and back again: metasomatic processes in ultramafic xenoliths from the Wesselton kimberlite, Kimbreley, South Africa. Contribs to Min. and Pet. 134, 232-250.

Harte, B., Fitzsimons, I.C.W., Kinny, P.D., 1996. Clinopyroxene-garnet trace element partition coefficients for mantle peridotite and melt assemblages. V.M. Goldschmidt Conference. J. of Conf. Abstr. 1, 235.

Hoal, K.E.O., Hoal, B.G., Erkland, A.J., Shimizu, N., 1994. Metasomatism of the mantle lithosphere recorded by rare earth elements in garnets. EPSL. 126, 303-313.

McKenzie, D., 1989. Some remarks on the movement of small melt fractions in the mantle. EPSL. 95, 53-72.

Shimizu, N., Sobolev, N.V., 1995. Young peridotitic diamonds from the Mir kimberlite pipe. Nature, 375. 394-397.

Shimizu, N., Kushiro, I., 1975. The partitioning of rare earth elements between garnet and liquid at high pressures: Preliminary experiments. Geophys. Res. Lets. 2, 413416.

Shimizu, N., Richardson, S.H., 1987. Trace element abundance patterns of garnet inclusions in peridotitesuite diamonds. Geochim. Cosmochim. Acta, 51, 755758.

Shimizu, N., 1999. Young geochemical features in Cratonic peridotites from Southern Africa and Siberia. The Geochem. Soc. Special Publn. 6, 47-55.

Van Orman, J.A., Grove, T.L., Shimizu, N., Layne, D., 2001b. Rare earth element diffusion in a natural pyrope single crystal. Contribs to Min. and Pet., 141.

Contact: Grant Institute of Geology and Geophysics, King's

Buildings, West Mains Road, Edinburgh, Scotland, United

Kingdom, EH9 3JW, E-mail: tim.ivanic@glg.ed.ac.uk,

ben.harte@glg.ed.ac.uk 